\title{
Young people who are being bullied - do they want general practice support?
}

\author{
Emma Scott ${ }^{1 *} \mathbb{D}$, Jeremy Dale ${ }^{1}$, Rachel Russell ${ }^{1}$ and Dieter Wolke ${ }^{2}$
}

\begin{abstract}
Background: Childhood bullying is a major risk factor for health, education and social relationships, with effects persisting into adulthood. It affects half of all children at some point, with 10-14 \% experiencing bullying that lasts for years. With the advent of cyberbullying, it can happen at all times and places. There have been calls for GPs to take a more active role in identifying and supporting young people who are being bullied. This paper explores young people's and parents' opinions about whether general practice should be involved in identifying and supporting young people who are being bullied.

Methods: Two hundred six young people (85.9\% female, mean \pm sd age $16.2 \pm 3.2$ years) and 44 parents were recruited through established bullying charity websites and their social media channels to complete an online questionnaire comprising multiple-choice questions and unlimited narrative responses. Questionnaire responses were analysed by age and gender using descriptive statistics. A descriptive analysis of the narrative responses was undertaken and key themes identified.

Results: Young people $(90.8 \%$ ) and parents $(88.7 \%)$ thought it was important for GPs to be better able to recognise and help young people who are being bullied. Most recognised the link between bullying and health. The doctor's independence was seen as advantageous. Young people preferred completing a screening questionnaire to disclose experience of being bullied than being asked directly. They expressed concerns about how questions would be asked and whether information would be shared with parents/guardians. Parents were supportive of the use of a screening questionnaire, and most expected their child's disclosure to be shared with them.
\end{abstract}

Conclusion: Young people and parents recruited through anti-bullying websites and social media would welcome greater GP involvement in identifying and supporting young people who are being bullied and their families, provided it is offered in a caring, compassionate and confidential manner.

Keywords: General practice, Bullying, Children, Parents, Questionnaire, Internet

Abbreviations: CAMHS, Child and Adolescent Mental Health Services; GP, General Practitioner; NICE, National Institute of Health and Care Excellence; RCGP, Royal College of General Practitioners; UK, United Kingdom; WHO, World Health Organisation; YP, Young Person

\section{Background}

Bullying is a systematic abuse of power characterised by repeated psychological or physical aggression with the intention to cause distress to another person. Over half of young people (55\%) report having recently been bullied [1], with 10-14 \% experiencing chronic bullying lasting for more than six months [2]. Bullying occurs at similar rates across all socio-economic strata $[1,3]$ with

\footnotetext{
* Correspondence: e.j.scott@warwick.ac.uk

${ }^{1}$ Warwick Medical School, University of Warwick, Coventry CV4 7AL, UK

Full list of author information is available at the end of the article
}

both minority ethnic and white youths reporting comparable levels of victimisation [4]. Although often perceived as a school-based problem, bullying is increasingly community-based. Social networking sites and smartphones have brought with them a new phenomenon cyber-bullying, which can happen at all times and in all places [5]. Recent figures show that $15 \%$ of 15 year olds in the UK have experienced cyber-bullying. Girls are more likely to experience psychological, emotional and cyber-bullying, whereas boys are more likely to be physically bullied [1]. 
Childhood bullying is a major risk factor for health, educational attainment and social relationships. Bullied children are twice as likely as non-victims to suffer from psychosomatic problems, such as headaches, abdominal pain, sleeping problems, poor appetite and enuresis [6]. They are at increased risk of psychiatric disorders including depression, eating disorders, self-harm and suicidal behaviour $[7,8]$. They also have high rates of poor academic performance resulting from absenteeism and worries at school $[9,10]$. Over 16,000 young people in the UK aged 11-15 years are estimated to be absent from state school with bullying as the main reason, and a further 78,000 are absent where bullying is one of the reasons given [11]. The adverse consequences of childhood bullying continue into adulthood leading to substantial health and wider societal costs. This includes difficulties with employment and social relationships, and mental health consequences such as general anxiety disorder, panic disorder, agoraphobia, depression, and suicidal acts [12].

General Practitioners (GPs) in the UK can offer supportive counselling either within the practice or from a third sector agency specialising supporting young people or bullying. They also have access to a range of other resources as recommended by the Royal College of General Practitioners (RCGP) [13]. If bullying is affecting the young person's education, the GP can refer them to the educational psychology service or to Children and Adolescent Mental Health Service (CAMHS) if there is evidence of severe mental health issues. In addition to this, GPs are optimally placed to identify and treat the physical and psychological consequences of bullying outlined above. Talking to someone about bullying is the first step to getting help, but up to $40 \%$ of children never disclose bullying to their parents [14]. Hence, the opportunity to discuss bullying with a healthcare professional may provide an important avenue to break the silence and initiate help.

Given the impact on health, children who are being bullied are likely to have greater need for health care than their non-bullied peers. Although research to confirm the extent to which this leads to more frequent attendance at general practice is lacking [15], previous work with school nurses has confirmed that there is a positive correlation between self-reported health symptoms (e.g. poor sleep, frequent headache) and frequency of bullying experienced [16, 17]. In the UK, school nurses do not typically consult with every student in the school every year. In countries, however, such as Denmark, where an annual consultation is routine, students who are being bullied are more likely to report positive effects of their dialogue with the school nurse and to initiate additional visits to the nurse [18]. The WHO has called for society-wide inter-agency approaches that include primary care and mental health services [19]. This has been echoed by NICE who include the evaluation of bullying as a risk factor and the development of antibullying strategies in several of its guidance documents, including depression [20] and weight management in young people [21] which specifically mention general practice. The Anti-Bullying Alliance, in collaboration with the Royal College of General Practitioners, marked AntiBullying Week 2015 with the publication of guidance notes for GPs [22].

Despite the calls for greater health service involvement, the extent to which young people and their families see bullying as a health issue relevant to general practice is unknown. This paper reports on work exploring the views of young people and parents about GPs taking a more active role in identifying and supporting young people who are being bullied.

\section{Methods \\ Recruitment}

Four national UK-based bullying charities (Anti-Bullying Alliance, BeatBullying, Bullies Out, Kidscape), which offer support to young people aged 11-25years, posted brief information on their websites, Facebook pages and twitter feeds, inviting young people who had experienced bullying to complete a brief survey. A hyperlink was provided to a page on the University's website where more detailed information about the study was given, together with a link to a confidential survey page.

There was no direct contact between researcher and participant. Parental consent was not obtained for the young people participating. Clicking the link given in the invitation from the charity and then completing the online survey after reading the age appropriate information supplied about how their responses would be used, was considered to be implied informed consent. The reason for not seeking parental consent was to ensure that potential participants who have not disclosed the fact that they are being bullied to a parent were not unfairly excluded from the survey. There are many reasons that young people may not tell their parents that they are being bullied and it is particularly important that their opinions on other sources of support are heard. Our institutional ethics review board approved this approach and the rationale behind it.

A parallel request was made for parents of children who had been bullied to complete a similar survey. No active effort was made to recruit parent-child dyads. Parental participation was not contingent on their child also completing the questionnaire and no information was collected to match parent and child participants. Completion of the survey, after reading the introductory information about how their responses would be used, was considered implied informed consent. 
The study received ethical approval from the University's BioSciences Research Ethics Committee.

\section{Data collection}

For young people, the survey comprised three multiple choice questions with free text space under each question. The questions were intended to stimulate interest, with topics covering the perceived importance of GP involvement in identifying and supporting children who are being bullied, and whether they would be comfortable with (a) their GP asking about bullying and (b) completing a screening questionnaire which included questions on bullying, in the waiting room prior to seeing the GP. The questions and answer options are presented in full in Table 1.

The parental survey had eight questions, three of which related to the bullying experienced by their child. The remaining questions covered the perceived importance of greater GP involvement, feelings about their child being asked to complete a screening tool for bullying, whether they thought their child would be honest about bullying if the GP asked and their experience of discussing bullying with their own GP. The questions and answer options are presented in full in Table 2.

Age and gender were collected for participants in both surveys.

The questions in both surveys were initially developed in consultation with representatives from the Anti-Bullying Alliance and Kidscape. The response options were refined with input from local parents and young people with experience of bullying. There was no formal pilot test phase.

\section{Data analysis}

For the multiple choice questions in both surveys, response frequencies were tallied. Chi-square tests were conducted to explore any differences in response by age or gender, with a $p$-value of less than 0.05 considered to be significant. All data analysis was conducted using IBM SPSS Statistics 22.

Free text responses were downloaded verbatim from the online survey output and initially collated by which survey question elicited the comment. The lead author familiarised herself with the responses before undertaking a descriptive analysis of the data. As this was exploratory work, an inductive approach was taken. The data was subjected to a process of complete coding and candidate themes identified. These themes were then refined, redundant themes removed and further themes added as identified during subsequent readings of the data. The relationship between the themes and participants' responses to the multiple choice questions was considered during analysis. As some themes were common to more than one question, the data was collapsed and the findings presented by theme.

\section{Results}

\section{Participant characteristics}

Two hundred and six young people (85.9\% female, mean \pm sd age $16.2 \pm 3.2$ years) and 44 parents $(88.6 \%$ female, aged 25-58 years) participated. The majority (55.4\%) of young people were aged $13-16$ years (see Fig. 1), and there was no difference in gender distribution by age $(p=.142)$.

Most parent participants $(86.4 \%)$ were certain that their child had been bullied, the others were less sure. Parents reported a wide range of types of bullying experienced by their child (see Table 2) with school bullying (86.4\%) being the most common. In the majority of cases (90.9\%) the child was aged 16 years or younger at the time.

\section{Quantitative data}

All multiple choice questions received a $100 \%$ response (see Tables 1 and 2). For young people, there were no differences in responses to any question by age (all $p>.495$ ) or sex (all $p>.119)$.

Table 1 Young people's responses to the multiple choice questions

\begin{tabular}{|c|c|c|c|c|}
\hline \multicolumn{5}{|c|}{ Q1: How important do you think it is for GPs to be better able to recognise and help young people who are affected by bullying? } \\
\hline Very important & Quite important & Not Sure & Not very important & Not important at all \\
\hline$n=109,52.9 \%$ & $n=78,37.9 \%$ & $n=11,5.3 \%$ & $n=7,3.4 \%$ & $n=1,0.5 \%$ \\
\hline \multicolumn{5}{|c|}{$\begin{array}{l}\text { Q2: As a young person, how would you feel if a GP asked you about experiences of being bullied if you were attending the GP for an everyda) } \\
\text { problem such as a headache or tummy ache? Would you feel comfortable with this? }\end{array}$} \\
\hline Yes, completely & Yes, a bit & Not sure & Not very much & Not at all \\
\hline$n=36,17.5 \%$ & $n=72,35.0 \%$ & $n=50,24.2 \%$ & $n=36,17.5 \%$ & $n=12,5.8 \%$ \\
\hline \multicolumn{5}{|c|}{$\begin{array}{l}\text { Q3: We are thinking of asking young people to complete a questionnaire while in the waiting room when they visit the doctor to ask about their } \\
\text { current health. This would include some questions about their experience of being bullied. Would you feel comfortable answering such a } \\
\text { questionnaire in the waiting room? }\end{array}$} \\
\hline Yes, completely & Yes, a bit & Not sure & Not very much & Not at all \\
\hline$n=100,48.5 \%$ & $n=68,33.0 \%$ & $n=15,7.3 \%$ & $n=17,8.3 \%$ & $n=6,2.9 \%$ \\
\hline
\end{tabular}


Table 2 Parents' survey responses

\begin{tabular}{|c|c|c|c|c|c|c|}
\hline \multicolumn{7}{|c|}{ Q1: Has your child ever been bullied? } \\
\hline \multicolumn{2}{|l|}{ Yes } & \multicolumn{3}{|l|}{ No } & \multicolumn{2}{|l|}{ Unsure } \\
\hline \multicolumn{2}{|l|}{$n=38,86.4 \%$} & \multicolumn{3}{|l|}{$n=4,9.1 \%$} & \multicolumn{2}{|l|}{$n=2,4.5 \%$} \\
\hline \multicolumn{7}{|c|}{ Q2: If you answered yes to Q1, what type of bullying was it? You may choose more than one option ${ }^{\text {a }}$} \\
\hline School & Outside school & Cyber & Emotional & Physical & Psychological & Other \\
\hline$n=38,86.4 \%$ & $n=18,40.9 \%$ & $n=11,25.0 \%$ & $n=20,45.5 \%$ & $n=14,31.8 \%$ & $n=13,29.5 \%$ & $n=2,4.5 \%$ \\
\hline \multicolumn{7}{|c|}{ Q3: Was your child aged 16 years or younger? } \\
\hline \multicolumn{2}{|c|}{ Yes - primary school } & Yes - secondary school & \multicolumn{2}{|c|}{ Yes - both schools } & Yes - age not given & No \\
\hline \multicolumn{2}{|l|}{$n=10,22.7 \%$} & $n=10,22.7 \%$ & \multicolumn{2}{|l|}{$n=4,9.1 \%$} & $n=20,45.5 \%$ & $n=2,9.1 \%$ \\
\hline \multicolumn{7}{|c|}{ Q4: Do you think it is important that GPs should be better able to recognise and help young people being affected by bullying? } \\
\hline \multirow{2}{*}{\multicolumn{2}{|c|}{ Very important }} & Quite important & \multicolumn{2}{|l|}{ Not Sure } & Not very important & Not important at all \\
\hline & $n=31,70.5 \%$ & $n=8,18.2 \%$ & \multicolumn{2}{|l|}{$n=5,11.3 \%$} & $n=0$ & $n=0$ \\
\hline
\end{tabular}

Q5: How would you feel if your child was asked to complete a questionnaire while in the doctor's waiting room which covered questions about their current health including their experience of being bullied?

\begin{tabular}{|c|c|c|c|}
\hline $\begin{array}{l}\text { Positive - would expect child } \\
\text { to share answers }\end{array}$ & $\begin{array}{l}\text { Positive - would not expect } \\
\text { child to share answers }\end{array}$ & Not Sure & $\begin{array}{l}\text { Negative }- \text { I don't think this } \\
\text { is appropriate }\end{array}$ \\
\hline$n=24,54.5 \%$ & $n=12,27.3 \%$ & $n=3,6.8 \%$ & $n=5,11.4 \%$ \\
\hline
\end{tabular}

Q6: If your child was being bullied do you think they would report this during a visit with a doctor if asked?

\begin{tabular}{|c|c|c|c|c|}
\hline Yes, definitely & Yes, maybe & Not sure & No, probably not & No, definitely not \\
\hline$n=6,13.6 \%$ & $n=18,40.9 \%$ & $n=9,20.5 \%$ & $n=9,20.5 \%$ & $n=2,4.5 \%$ \\
\hline
\end{tabular}

Q7: What kind of problem do you see bullying as? You may choose more than one option ${ }^{\text {a }}$

$\begin{array}{llll}\text { School } & \text { Health } & \text { Neither } & \text { Other } \\ n=33,75.0 \% & n=23,52.3 \% & n=1,2.3 \% & n=17,38.6 \%\end{array}$

Q8: Have you ever discussed with a GP any incidents of bullying of your child and its consequences?

$$
\begin{array}{llll}
\text { Yes - GP helpful } & \text { Yes - GP not helpful } & \text { No } & \text { Not yet, but am considering } \\
n=7,15.9 \% & n=9,20.5 \% & n=26,59.1 \% & n=2,4.5 \%
\end{array}
$$

${ }^{a}$ Note: parents were able to select more than one type of bullying so percentages will not add up to $100 \%$

\section{Involvement of GPs}

Most young people thought it important (very important $52.9 \%$; quite important $37.9 \%$ ) for GPs to be better able to recognise and help young people who are affected by bullying. Likewise, most parents also believed this to be important (very important $70.5 \%$; quite important $18.2 \%$ ).

Just over half of the young people described feeling comfortable (completely comfortable $17.5 \%$; quite comfortable $35.0 \%$ ) with their GP asking about bullying if they attended the surgery for a problem such as a headache. A quarter, however, would not be comfortable being asked (not very comfortable $17.5 \%$; not at all comfortable $5.8 \%$ ) and the remaining $24.2 \%$ were uncertain. This pattern of responses was similar across all age ranges $(p=.495)$.

Most parents recognised bullying as a school and/or health problem, with a significant proportion (38.6\%) identifying additional or alternative routes of the problem, i.e. social/community problem $(n=8)$, cyber- bullying $(n=2)$, family problem $(n=2)$, a self-esteem problem $(n=1)$, "a fact of life" $(n=1)$.

Over a third of parents (36.4\%) had discussed the bullying of their child and its consequences with their GP, but less than half had found it helpful.

\section{Screening for bullying}

When asked about completing a health questionnaire, which included questions about bullying, before seeing a GP, the vast majority of young people would feel comfortable doing this (completely comfortable $48.5 \%$; quite comfortable $33.0 \%$ ). A few were unsure (7.3\%) and some were not comfortable with this idea (not very comfortable $8.3 \%$; not at all comfortable $2.9 \%$ ).

The vast majority $(81.8 \%)$ of parents were positive about the idea of their child being asked to complete a screening questionnaire that included questions on bullying. Most would expect their child to show them their answers. 


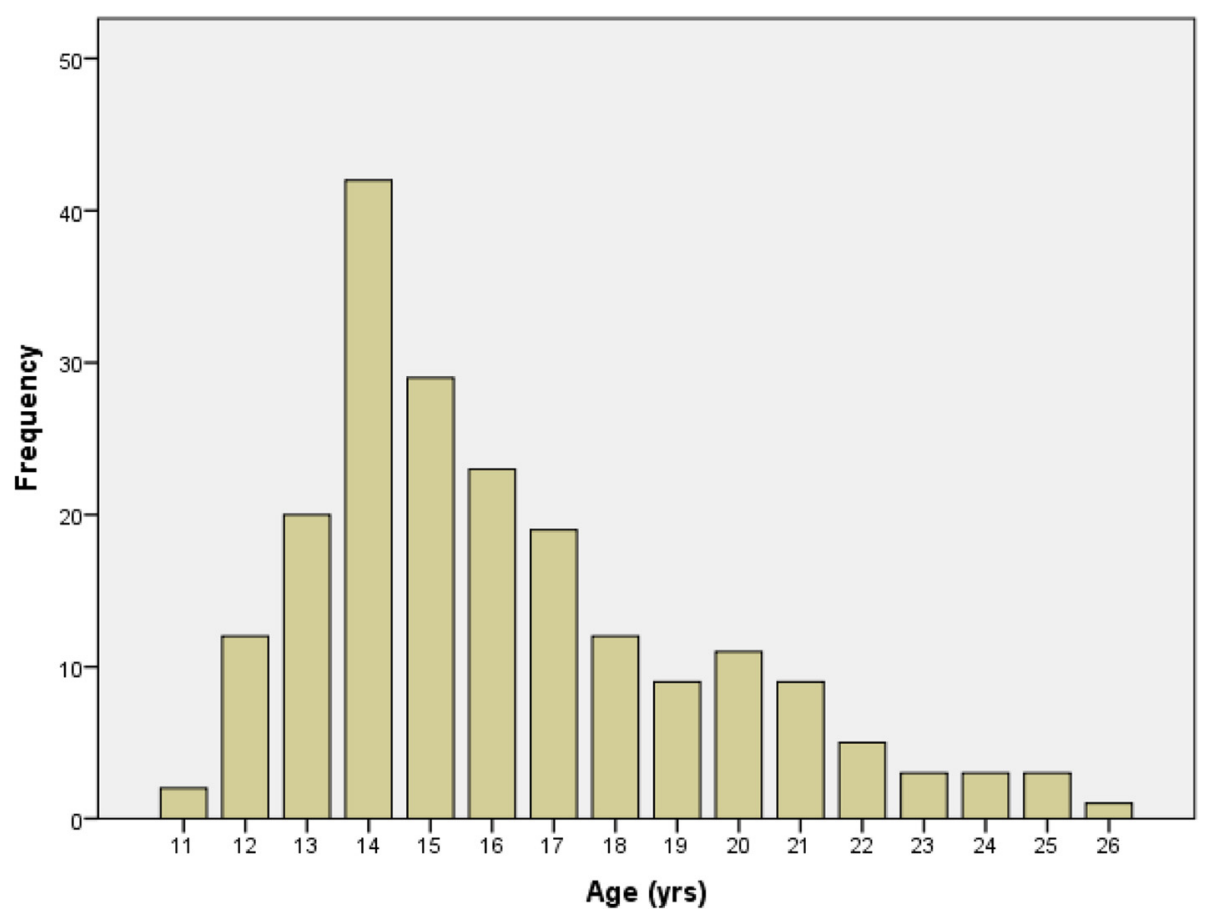

Fig. 1 Age distribution of young people completing the questionnaire

\section{Qualitative data}

In total, young people provided 232 free text comments with a further 56 from parents. Most were quite brief (1020 words) but others were notably longer (up to 700 words). Analysis identified four themes: Awareness of the link between bullying and health; The appropriateness of GP involvement; Confidentiality and the presence of parents; and, Practical issues surrounding screening.

\section{Awareness of the link between bullying and health}

Most young people and parents demonstrated understanding that bullying can be a cause or contributory factor in both physical and mental ill-health throughout the comments they provided. In many cases they spoke from experience and included personal examples. A minority, however, appeared unaware of bullying as a potential risk factor for common health concerns:

\section{"I don't really see the link between GP and bullying.} If I go in with a tummy ache or headache I would just want to get in there get medication and then come out." (Young Person \#85, female, aged 14)

Experience of approaching the GP for support with bullying-related health problems was variable. GPs were perceived to lack understanding of bullying and its links to physical and mental health. Parents were particularly critical:
"A medical problem may well be the first sign of bullying ... it would be helpful if GPs were more aware of how prevalent bullying is and included it in any assessment of the child." (Parent \#43, female, aged 52)

\section{The appropriateness of GP involvement}

Whilst both young people and parent participants were overwhelmingly in favour of GPs being better able to identify and support young people who are being bullied, they also expressed a number of reservations. A very small minority felt that tackling bullying was outside the doctor's remit and should remain the responsibility of teachers and parents.

Both young people and parents thought GPs being removed from the school setting was an advantage. The doctors' independence from both the family and school was considered beneficial and likely to allow a more objective assessment of the child and situation. In addition to this, young people felt it would be easier to talk to a more independent adult:

"...it may be easier to talk to someone that they know probably doesn't know the people they are talking about and that they won't tell them."

(Young Person \#20, female, aged 14)

Over half of the parents surveyed thought that if their child was being bullied that they would probably tell the 
doctor, if asked, and those leaving comments identified the doctor's approach to questioning as being key to facilitating disclosure. Parents and young people agreed that they would be more likely to report bullying if they understood why the doctor was asking (i.e. the link between bullying and health). Other key factors were GP sensitivity and offering reassurance:

\section{"As long as they were friendly and genuine I would quite happily talk about problems if someone was there to listen. I wouldn't talk if it was spoken about in a generic way like a check mark against their daily tasks." (YP \#176, female, 22)}

Young people felt the most significant barrier to disclosure was the feeling that they didn't have an established relationship with their GP. They expressed concern about their lack of connection with their doctor and the difficulties this may present in feeling safe talking to them:

\section{"You might not even want to tell an adult you trust, let alone one that you don't really know" \\ (YP \#138, female, 13)}

Other concerns expressed by both young people and parents included whether GPs have the appropriate training and experience to deal with bullying and the time pressure of brief appointment slots.

\section{Confidentiality and the presence of parents}

A significant number of young people expressed a preference for the questionnaire being anonymous, but in the context of the comments it appears that there may have been some confusion between the terms 'anonymous' and 'confidential':

"I know that this would be kept completely anonymous between myself and the doctor..." (YP \#20, female, 14)

While participants acknowledged the link between bullying and health and understood that the doctor would be trying to help, some felt that being asked about bullying might be uncomfortable or awkward, but could offer a means of relief:

"I would personally feel weird and in an awkward position. However if one person does know about my situation they may help me and I may not be a victim any more. (YP \#9, female, 14)

Discomfort was expected to be greater if their parents were present and a few young people questioned whether children would disclose bullying in their parent's presence. Many young people expressed a preference for parents/ carers not to be present during discussions about bullying.

Most parents, however, expected their child's disclosure to be shared with them and some expressed a desire to be the first person to help their child. Others gave a more balanced view about providing support to the child:

"Would hope that my child would share info with me, but it is important that they know it would be confidential if they wish." (Parent \#43, female, 52)

\section{Practical issues surrounding screening}

Participants identified a number of practical issues regarding the use of a screening questionnaire to identify young people who are being bullied including delivery format and venue. There was a strong preference among young people for initially answering questions about bullying in a paper or online questionnaire rather than verbally face-to-face:

"I think this would be a more suitable and effective way of approaching this topic ... it's easier to write things down than speak to someone"

(YP \#92, female, 17)

Young people's opinions were divided on the appropriateness of completing the questionnaire in the GP's waiting room. Some participants felt that this was a good way of asking and that completing the questionnaire in the waiting room would result in better engagement.

"I would feel comfortable answering a questionnaire in the waiting room as it gives me something to do while I'm waiting ... I think it would then be easier to speak to the GP about when you went in" (YP \#126, female, 16)

But others, while positive about the idea of completing the questionnaire, raised concerns about privacy in the waiting room and suggested alternatives, such as completing it at home or online.

Parental concerns were focussed on the possibility of the questionnaire causing distress to a child, while others questioned whether a child would complete the questionnaire honestly. It was observed that the questionnaire would only be of use if the doctor valued the questions and the responses provided.

\section{Discussion}

Both young people and parents recognised the link between bullying and health, and would welcome greater GP involvement in recognising and supporting young 
people who are being bullied, providing this was done in a caring and compassionate way. Young people viewed the completion of a paper or online screening questionnaire prior to the appointment as preferable to initially being asked about bullying face-to-face; parents also found this approach acceptable. Parents and young people disagreed about whether parents should be present during the discussion about bullying.

These are important findings considering that up to $40 \%$ of children never disclose bullying to their parents [14], but that talking to someone about bullying is the first step towards help. Thus confidential disclosure to GPs may provide an important avenue to break the silence and initiate help. This may be in the form of counselling or support from the GP to manage the physical and psychological consequences of bullying, or referral to specialist services such as the educational psychology service or CAMHS [13].

Given the preference expressed by young people to complete a screening questionnaire rather than being asked directly about bullying, alternative routes to follow up with young people identified through screening should also be explored. Previous research has found school nurses to be a viable way of identifying and supporting young people who are being bullied $[16,18]$. For this model to work in the UK, school nurses would need to be a more regular fixture in schools so that they are a trusted face rather than an infrequent visitor. The participants in this study placed significant value on the doctor's independence from the school. Hence, the GP practice nurse might also provide an appropriate source of support.

Both parents and young people expressed concerns about how the GP would facilitate disclosure of bullying. The qualitative findings suggest that GPs may need to be more attuned to the importance of (a) considering a young person's experience of bullying as a risk factor for poor physical and mental health, (b) building a trusting relationship with their young patients, (c) ensuring that enquiries about bullying are made in a caring and compassionate way; and (d) that young people are given their full attention when talking about bullying experiences. While many GPs may feel that they already seek to do these things, it still remains that these are the areas where young people and parents see room for improvement.

The discrepancy between young people's and parents' views related to parental presence when questions about bullying were being asked needs to be addressed. Most parents expected their child's responses to be shared with them, but many young people expressed a preference for parents/carers not to be present during discussions about bullying. Similar research conducted with GPs has shown that the presence of a parent may also affect their willingness to initiate discussion of a potentially sensitive topic [23].

\section{Strengths and limitations}

To our knowledge, this is the first report of young people's and parents' perspectives on the involvement of GPs in identifying and supporting young people who are being bullied.

The use of brief questions accompanied by unlimited text boxes allowed participants to expand on their questionnaire answers and put them into context. This combined approach resulted in a richer and more illuminating data set than is usually possible using survey methods alone and reached a greater number of participants than would typically be possible for traditional qualitative work. The quantity of free text responses received was unanticipated and what was originally expected to be a brief quantitative survey became a mixed methods study.

Data analysis was carried out by a single researcher. While her perspective may have influenced interpretation of the data, the accompanying quantitative data from each participant clarifies their point of view (positive, negative, uncertain) on each question, thereby reducing the risk of misinterpretation.

Recruiting participants through established bullying charity social media channels was an effective means of involving individuals with a diverse range of experience. Distributing paper questionnaires through schools or youth groups would likely have drawn a minority of participants with first-hand experience of chronic bullying. The use of an online survey also allowed greater preservation of participant anonymity. The use of different online research methods in health services research has been discussed in detail elsewhere [24, 25].

The main limitation of the sample is that the extent to which it is representative of the wider population of bullied young people and their parents is unknown. As recruitment was undertaken through bullying charity websites, the sample may have been biased towards individuals who are already actively seeking support to cope with bullying and may therefore be more receptive towards alternative sources of support, such as GPs. Furthermore the sample was predominantly female and, although girls are more likely to be bullied than boys [1], the difference is not as pronounced as the imbalance in our sample. In addition to this, girls and boys typically experience different types of bullying [1] and we did not collect any information on the type of bullying experienced by the participants. Although we observed no differences in the responses recorded by age or gender on this occasion, this does not mean that the results are necessarily generalizable to all bullying victims. Further work is needed to explore the opinions 
of young males who have been bullied and efforts should be made to obtain data on the types of bullying experienced by participants.

\section{Conclusion}

This study reinforces calls for greater GP involvement in preventing the long term health consequences associated with childhood bullying $[15,19,26,27]$, and provides evidence that young people and their parents would welcome this. It provides new knowledge that young people would prefer to complete a screening questionnaire in the waiting room before the consultation, rather than be asked about bullying face-to-face. It is important that any future screening or support programme involving general practice would need to be acceptable to the intended recipients with confidential screening being a potentially acceptable way.

The focus of this paper is whether young people who are being bullied and their parents want GP support. Further work is also needed to explore how that support should be provided.

\section{Acknowledgements}

The authors would like to thank the charities who assisted with recruitment, Anti-Bullying Alliance, BeatBullying, Bullies Out and Kidscape, and the parents and young people who took the time to provide their opinions on this topic.

\section{Funding}

This research received no specific grant from any funding agency in the public, commercial or not-for-profit sectors.

\section{Availability of data and materials}

Informed consent for data publication has not been obtained and due to the anonymous nature of the data, it is not possible to re-contact participants to ask for consent. The qualitative data collected explores a sensitive topic (being a victim of bullying) and contains a number of indirect identifiers, removal of which would significantly influence and impact the data set. As such, the data will not be placed in a public repository but will be made available upon request from the lead author.

\section{Authors' contributions}

JD and RR conceived the study, RR collected the data, ES analysed and interpreted the data. ES drafted the initial report before JD, RR and DW made critical revisions. All authors read and approved the final manuscript.

\section{Competing interests}

The authors declare that they have no competing interests.

\section{Consent for publication}

No individual patients' data is included in an identifiable format. All participants were aware that free text responses given may be used in an anonymised form

\section{Ethics approval and consent to participate}

The study received ethical approval from the University of Warwick's BioSciences Research Ethics Committee (REC ref no.: REGO-2013-577). The survey was anonymous and participants were recruited online without any direct researcher contact. Thus, completion of the online survey, after reading the introductory information about how their responses would be used, was considered implied informed consent.

\section{Author details}

${ }^{1}$ Warwick Medical School, University of Warwick, Coventry CV4 7AL, UK.

${ }^{2}$ Department of Psychology, University of Warwick, Coventry CV4 7AL, UK.
Received: 15 April 2016 Accepted: 16 August 2016

Published online: 22 August 2016

\section{References}

1. Health \& Social Care Information Centre. Health and Wellbeing of 15 year olds in England: Findings from the What About YOUth? Survey 2014. 2015. http://digital.nhs.uk/catalogue/PUB19244. Accessed 08 Dec 2015.

2. World Health Organization. Risk behaviours: being bullied and bullying others. In: Currie C, Zanaotti C, Morgan A, et al., editors. Social determinants of health and well-being among young people. Health Behaviour in Schoolaged Children (HBSC) study: International report from the 2009/2010 survey. Copenhagen: WHO Regional Office for Europe (Health Policy for Children and Adolescents, No. 6); 2012. p. 191-200.

3. Due P, Meno J, Harel-Fisch Y, Damsgaard MT, Holstein BE, Hetland J, Currie C, Gabhainn SN, de Matos MG, Lynch J. Socioeconomic inequality in exposure to bullying during adolescence: a comparative, cross-sectional, multilevel study in 35 countries. Am J Public Health. 2009;99(5):907-14.

4. Tippett N, Wolke D, Platt L. Ethnicity and bullying involvement in a national UK youth sample. J Adolesc. 2013;36(4):639-49.

5. Smith PK, Mahdave J, Carvelho M, Fisher S, Russell S, Tippett N Cyberbullying: its nature and impact in secondary school pupils. J Child Psychol Psychiatry. 2008:49(4):376-85.

6. Gini G, Pozzoli T. Association between bullying and psychosomatic problems: a meta-analysis. Pediatrics. 2009;123(3):1059-65.

7. Lereya ST, Winsper C, Heron J, Lewis G, Gunnell D, Fisher HL, Wolke D. Being bullied during childhood and the prospective pathways to selfharm in late adolescence. J Am Acad Child Adolesc Psychiatry. 2013;52:608-18

8. Wolke D, Lereya ST, Fisher HL, Lewis G, Zammit S. Bullying in elementary school and psychotic symptoms at 18 years: a longitudinal populationbased cohort study. Psychol Med. 2013;44(10):2199-211.

9. Wolke D, Copeland WE, Angold A, Costello EJ. Impact of bullying in childhood on adolescent health, wealth, crime and social outcomes. Psychol Sci. 2013;24:1958-70

10. Nakamoto J, Schwartz D. Is peer victimisation associated with academic achievement? A meta-analytic review. Soc Dev. 2010;19:221-42.

11. Brown V, Clery E, Ferguson C. Estimating the prevalence of young people absent from school due to bullying. Natl Cent Soc Res. 2011;1:1-61.

12. Copeland WE, Wolke D, Angold A, Costello E. Adult psychiatric outcomes of bullying and being bullied by peers in childhood and adolescence. JAMA Psychiatry. 2013;70(4):419-26.

13. Royal College of General Practitioners. A to Z Clinical Resources - Youth Mental Health. http://www.rcgp.org.uk/clinical-and-research/a-to-z-clinicalresources/youth-mental-health.aspx. Accessed 25 May 2016

14. Chamberlain T, George N, Golden S, Walker F, Benton T. Tellus4 National Report. Colchester: UK Data Archive; 2010

15. Dale J, Russell R, Wolke D. Intervening in primary care against childhood bullying: an increasingly pressing public health need. J R Soc Med. 2014;107:219-23.

16. Williams K, Chambers M, Logan S, Robinson D. Association of common health symptoms with bullying in primary school children. BMJ. 1996:313:17-9.

17. Fekkes M, Pijpers FIM, Veloove-Vanhorick SP. Bullying behaviour and associations with psychosomatic complaints and depression in victims. J Pediatr. 2004;144:17-22.

18. Borup I, Holstein BE. Schoolchildren who are victims of bullying benefit from health dialogues with the school health nurse. Health Educ J. 2007;66:58-67.

19. Scrabstein JC, Leventhal BL. Prevention of bullying-related morbidity and mortality: a call for public health policies. Bull World Health Organ. 2010;88: 403. doi:10.2471/BLT.10.077123.

20. National Institute of Health and Care Excellence. Depression in children and young people: Identification and management in primary, community and secondary care - NICE Clinical Guideline 28 (CG28). 2005. https://www.nice. org.uk/guidance/cg28. Accessed 13 Nov 2014

21. National Institute of Health and Care Excellence. Managing overweight and obesity among children and young people: lifestyle and weight management services - NICE Public Health Guidance 47 (PH47). 2013. https://www.nice.org.uk/guidance/ph47. Accessed 13 Nov 2014.

22. Anti-Bullying Alliance. Bullying - A short guide for GPs. 2015. http://www. anti-bullyingalliance.org.uk/media/34573/Advice-for-GPs-final-November2015.pdf. Accessed 03 Dec 2015. 
23. Fox F, Stallard P, Cooney G. GPs role identifying young people who selfharm: a mixed methods study. Fam Pract. 2015;32(4):415-9.

24. Walker D. The internet as a medium for health service research. Part 1. Nurse Res. 2013;20(4):18-21.

25. Walker $\mathrm{D}$. The internet as a medium for health service research. Part 2. Nurse Res. 2013;20(5):33-7.

26. Klein DA, Myhre KK, Ahrendt DM. Bullying among adolescents: a challenge in primary care. Am Fam Physician. 2013;88(2):87-92.

27. Lamb D, Pepler D, Craig W. Clinical review: approach to bullying and victimisation. Can Fam Physician. 2009;55:356-60.

Submit your next manuscript to BioMed Central and we will help you at every step:

- We accept pre-submission inquiries

- Our selector tool helps you to find the most relevant journal

- We provide round the clock customer support

- Convenient online submission

- Thorough peer review

- Inclusion in PubMed and all major indexing services

- Maximum visibility for your research

Submit your manuscript at www.biomedcentral.com/submit
Biomed Central 